\title{
Penerapan Kesehatan Dan Keselamatan Kerja Pada Wisata Paralayang Di Gunung Banyak, Kota Batu, Provinsi Jawa Timur
}

Muhammad Alif Adz Dzikri a,1, Made Sukana a, 2

1 adzdzikrialif@gmail.com, ${ }^{2}$ madesukana@unud.ac.id

a Program Studi Sarjana Destinasi Pariwisata, Fakultas Pariwisata,Universitas Udayana, Jl. Dr. R. Goris, Denpasar, Bali 80232 Indonesia

\section{Abstract}

The aim of this study is to analyze the workplace health and safety of the employee and visitor of Paragliding Tourism at Gunung Banyak, Batu East Java. This recreation has become the new tourist attraction for both domestic and international tourists. This makes the basis of this study to identify the factors that cause the accidents may happen to the employee and visitor, as well as the prevention done to minimize it and how to handle it when actually happens.

The data used is the qualitative data, while the source taken from primary and secondary data. The data collecting process are conducted through an observation, interview and literature review. The data are analyzed qualitatively. The result shows that Health and Safety procedure in Paragliding Tourism is the main thing as most of it has been applied on the field. However, some improvements are still needed in the procedure for the maximum safety of both employee and visitor.

The suggestion given to the owner of the Paragliding Recreation is to continue to watch the implementation of health and safety of Paragliding Tourism. As for the visitors are also suggested to always follow the rules and the instructor's direction. The writer hopes this study will give brief summary of the implementation of health and safety procedure at the Paragliding Toursm, and will eventually be useful for the next more detailed study.

Keywords: Paragliding Tourism, workplace health and safety, Mount Banyak of Batu City.

\section{PENDAHULUAN}

Kesehatan dan keselamatan kerja adalah hal yang penting untuk diperhatikan dalam kegiatan apapun, dalam dunia pariwisata banyak kegiatan wisata yang ditawarkan oleh pelaku bisnis pariwisata, dalam hal ini wisatawan maupun perusahaan yang menawarkan kegiatan wisata harus benarbenar memperhatikan keamanan pada jenis wisata yang ditawarkan karena berhubungan dengan kesehatan dan keselematan kerja dari wisatawan itu sendiri dan pihak lainnya sebagai penanggung jawab dari kegiatan wisata yang ditawarkan. Karena itu, suatu kegiatan wisata yang dibangun oleh pihak swasta ataupun pemerintah harus menerapkan prosedur standarisasi kesehatan dan keselamatan kerja yang sudah diakui, dan juga wisatawan harus benar-benar teliti dalam menentukan jenis kegiatan wisata seperti apa yang aman untuk dilakukan.

Kota Batu Jawa Timur adalah salah satu kota yang memanfaatkan kegiatan pariwisata sebagai ajang promosi untuk memperkenalkan daerahnya kepada masyarakat khususnya wisatawan yang ingin menikmati keindahan alam dan juga menikmati atraksi wisata. Di Kota Batu terdapat jenis kegiatan wisata ekstrim yang sudah cukup dikenal oleh wisatawan mancanegara maupun domestik yaitu wisata paralayang, jenis kegiatan wisata ini terletak di Gunung Banyak yang memang sangat mendukung untuk dilakukannya jenis wisata ini, selain karena pemandangan yang indah, Gunung Banyak juga terletak di dataran tinggi yang juga mendukung untuk terlaksananya jenis wisata ini. Daerah atau lokasi ini juga kemudian berkembang menjadi daerah tujuan wisata dengan sarana dan prasarana penunjang pariwisata.

Meskipun kegiatan wisata paralayang sudah banyak dikenal oleh wisatawan, pihak pengelola maupun wisatawan harus tetap memperhatikan prosedur kesehatan dan keselamatan kerja yang diterapkan pada wisata paralayang itu sendiri. Hal tersebut untuk mengantisipasi terjadinya kecelakaan yang tentunya tidak diinginkan. Dengan demikian penelitian penerapan prosedur kesehatan dan keselamatan kerja pada aktivitas wisata paralayang di Gunung Banyak, Kota Batu, Jawa Timur penting untuk dilakukan. Tujuan penelitian ini adalah untuk mengetahui mengetahui penerapan prosedur Kesehatan dan Keselamatan Kerja Wisata Paralayang pada instruktur, karyawan dan wisatawan, serta untuk mengetahui faktor-faktor yang dapat menyebabkan kecelakaan pada wisata paralayang dan cara pencegahan serta 
penanggulangan jika terjadi kecelakaan pada wisata paralayang.

\section{KEPUSTAKAAN}

\subsection{Telaah Hasil Penelitian Sebelumnya}

Penelitian sebelumnya dari Simon (2016) yang berjudul "Penerapan Keselamatan Dan Kesehatan Kerja Pada Aktivitas Wisata Berenang Bersama Ikan Hiu (swim with shark) Di Pulau Serangan, Denpasar Selatan". Dalam penelitian ini dijelaskan faktor pemicu terjadinya kecelakaan, akibat atau dampak yang ditimbulkan dan pencegahan serta penanggulangan yang berada pada atraksi wisata berenang dengan ikan hiu di Pulau Serangan, Kota Denpasar.

Telaah penelitian selanjutnya yaitu oleh Nila Restu Wardani (2011) dengan judul "Pengembangan Objek Wisata Paralayang Berdasarkan Kajian Geografis di Kota Batu". Dalam penelitian ini menjelaskan bahwa Gunung Banyak memiliki potensi untuk dijadikan objek wisata paralayang namun tetap memiliki kelebihan dan kekurangan, kelebihan dari lokasi Gunung Banyak adalah memiliki arah angin yang datang berlawanan dengan arah hadap lereng, sementara kekurangan dari lokasi Gunung Banyak terdapat pada tingkat kemiringan lerengnya yang hanya $25 \%$.

Penelitian oleh Kusuma dan Suryawan (2016) yang terbit dalam jurnal yang berjudul "Penerapan Keselamatan Dan Kesehatan Kerja Balawista Di Pantai Kuta". Dalam jurnal ini menjelaskan bahwa penerapan keselamatan dan kesehatan kerja pada balawista di Pantai Kuta sudah sesuai dengan standar yang ditentukan, serta adanya faktor-faktor yang mempengaruhi beban kerja balawista diantaranya adalah faktor eksternal yang meliputi lingkungan kerja dan kondisi alam, berikutnya faktor internal yang meliputi cara kerja dari balawista itu sendiri.

\subsection{Landasan Konsep dan Teori Analisis}

Berikut adalah konsep yang digunakan pada penelitian ini:

\section{Kesehatan dan Keselamatan Kerja (K3)}

Menurut Mangkunegara (2003 : 161) keselamatan dan kesehatan kerja adalah kondisi yang aman atau selamat dari penderitaan, kerusakan atau kerugian ditempat kerja. Resiko keselamatan kerja merupakan aspek-aspek dari dari lingkungan kerja yang dapat menyebabkan kebakaran, ketakutan aliran listrik, terpotong, luka memar, keseleo, patah tulang, kerugian alat tubuh, penglihatan dan pendengaran.

2. Atraksi Wisata.

Menurut Chaplin (2008) atraksi adalah sesuatu yang mempunyai beberapa kualitas yang mampu mendatangkan tingkah laku yang menyebabkan adient behavior yaitu kecendrungan untuk mendekati sumber. Sementara Oka.A.Yoeti (2002) berpendapat bahwa atraksi wisata adalah segala sesuatu yang dapat menarik wisatawan untuk berkunjung pada suatu daerah tujuan wisata.

3. Penerapan Kesehatan dan Keselamatan

Kerja.

Menurut Susilo (2007: 174) dalam Imam Mawardi (2009: 1) Implementasi (penerapan) merupakan suatu penerapan ide, konsep, kebijakan, atau inovasi dalam suatu tindakan praktis sehingga memberikan dampak, baik berupa perubahan dampak, berupa perubahan pengetahuan, keterampilan maupun nilai, dan sikap. Dari pendapat diatas dapat disimpulkan bahwa penerapan (implementasi) merupakan suatu aktivitas untuk menjalankan suatu program yang sudah disiapkan untuk menjapai suatu tujuan yang diinginkan.

Penerapan K3 memiliki beberapa tujuan dalam proses pelaksanaannya, berdasarkan Undang-Undang No.1 Tahun 1970 tentang Keselamatan Kerja. Terdapat 3 (tiga) tujuan utama dalam proses penerapan K3 yaitu:

a. Melindungi dan menjamin keselamatan setiap tenaga kerja dan orang lain di tempat kerja.

b. Menjamin setiap sumber produksi dapat digunakan secara aman dan efisien.

c. Meningkatkan kesejahteraan dan produktivitas Nasional.

Sehingga penerapan K3 adalah cara atau aktivitas untuk menjalankan program guna melindungi dan menjamin keselamatan setiap tenaga kerja/wisatawan, menjamin sumber produksi secara efisien dan menjamin kesejahteraan produktivitas nasional.

\section{III.METODE PENELITIAN}

Penelitian ini dilaksanakan di Gunung Banyak tepatnya pada wisata paralayang. Lokasi ini tepatnya berada di Jalan. 
Songgokerto, Songgokerto, Kec. Batu, Kota Batu, Provinsi Jawa Timur. Metode pada penelitian ini menggunakan deskriptif kualitatif dan jenis data yang digunakan adalah data kualitatif. Sumber data pada penelitian ini yaitu data primer yang ada di lokasi penelitian dan data sekunder yaitu data monografi Kota Batu. Teknik pengumpulan data menggunakan observasi, studi kepustakaan dan wawancara dengan informan yaitu pengelola paralayang gunung banyak, anggota asosiasi paralayang Gunung Banyak, master tandem/instruktur serta wisatawan. Teknik analisis data dilakukan dari pengumpulan data, reduksi data, penyajian data dan verifikasi data.

\section{HASIL DAN PEMBAHASAN}

\subsection{Gambaran Umum Paralayang Gunung Banyak}

Usaha tandem paralayang di Gunung Banyak dimulai pada tahun 90an tepatnya tahun 1995 di mana tahun itu adalah awal mula dari pencarian lokasi yang cocok dan tepat untuk dijadikan landasan terbang. Setelah melakukan pencarian lokasi selama satu tahun, akhirnya lokasi yang dipilih adalah Gunung Banyak yang terletak di Kota Batu dan berdekatan dengan Kota Malang di Provinsi Jawa Timur. Ditetapkannya lokasi ini karena Gunung Banyak memiliki tingkat kemiringan tanah yang mendukung untuk dijadikan landasan terbang atraksi wisata paralayan dan pada tahun 1997 adalah untuk pertama kalinya lokasi Gunung Banyak dijadikan tempat untuk landasan terbang untuk olahraga dirgantara ini. Pada tahun 1998 akhirnya wisata paralayang resmi dibuka untuk wisatawan dan pada tahun yang sama juga diadakan kejuaraan paralayang di lokasi Gunung Banyak.

Wisata paralayang di Gunung Banyak sendiri dikelola oleh Asosiasi Tandem Paralayang Gunung Banyak, yang terdiri atas 16 anggota structural dan 4 orang crew. Misi utama dari pihak pengelola adalah mengembangkan paralayang khusunya di Kota Batu Jawa Timur.

\subsection{Penerapan K3 Pada Aktivitas Wisata Paralayang}

\subsubsection{Penerapan K3 Pada Karyawan atau Pemandu Wisata}

Adapun penerapan K3 yang dilakukan oleh pihak pengelola wisata paralayang terhadap instruktur/pemandu wisata adalah dengan menetapkan syarat-syarat berikut:

a. Pihak pengelola wisata paralayang memastikan semua yang terlibat langsung dengan aktivitas wisata ini harus memiliki kondisi fisik yang sehat jasmani dan rohani.

b. Instruktur atau pemandu wisata pada aktivitas wisata paralayang harus memiliki keahlian pada olahraga atau aktivitas paralayang dan yang terpenting setiap instruktur atau pemandu harus memiliki lisensi yang dikeluarkan langsung oleh FASI dan minimal berada pada tingkatan T2 komersil.

c. Sebelum mendapatkan lisensi T2 komersil, setiap instruktur ataupun pemandu wisata harus melewati banyak tahapan agar bisa membawa wisatawan terbang, beberapa tahapannya adalah:

1. PL1: Novice Pilot

2. PL2: Intermediate Pilot

3. PL3: Advanced Pilot

4. T1: Tandem 1

5. T2: Tandem 2

6. T3: Tandem Instruktur

7. INST: Instruktur

8. J: Judge

d. Pihak pengelola wisata paralayang juga memberikan asuransi bagi setiap orang yang terlibat pada aktivitas wisata paralayang baik itu pengelola itu sendiri maupun instruktur atau pemandu wisata.

e. Setiap instruktur atau pemandu wisata yang akan melakukan kegiatan tandem pada aktivitas wisata paralayang harus menggunakan peralatan pengaman (safety) yang sudah ditentukan sesuai dengan standar operasional prosedur.

Instruktur atau pemandu wisata pada aktivitas wisata paralayang harus memperhatikan prosedur kesehatan dan keselamatan kerja karena aktivitas wisata ini termasuk dalam salah satu aktivitas wisata yang berbahaya. 


\subsubsection{Penerapan K3 Pada Wisatawan}

Pihak pengelola wisata paralayang memberikan persyaratan dan aturan kepada wisatawan sebelum melakukan kegiatan wisata paralayang dan diberikan beberapa instruksi terkait wisata paralayang.

1. Syarat

a. Usia yang diperbolehkan untuk melakukan aktivitas wisata paralayang tidak dibatasi selama wisatawan yang ingin melakukan aktivitas wisata paralayang merasa siap dan sanggup.

b. Wisatawan yang melakukan aktivitas wisata paralayang tidak memiliki penyakit atau dalam kondisi fisik yang sehat dan siap untuk melakukan aktivitas wisata paralayang.

c. Wisatawan yang ingin melakukan aktivitas wisata paralayang tidak boleh memiliki berat badan maximal yang sudah ditentukan oleh pihak pengelola yaitu $90 \mathrm{~kg}$.

d. Wisatawan yang ingin melakukan aktivitas wisata paralayang tidak boleh memiliki penyakit jantung.

e. Wisatawang yang ingin melakukan aktivitas wisata paralayang tidak boleh memiliki phobia pada ketinggian.

f. Wisatawan dilarang melakukan sesuatu diluar dari instruksi yang telah diinstruksikan oleh instruktur atau pemandu wisata selama melakukan aktivitas wisata paralayang.

g. Wisatawan wajib menggunakan peralatan pengaman diri, seperti helm, sepatu, dan harness (tempat duduk) untuk keselamatan selama melakukan aktivitas wisata paralayang.

2. Instruksi (arahan)

Beberapa arahan atau instruksi yang diberikan oleh instruktur atau pemandu wisata paralayang antara lain:

a. Mengkonfirmasi kembali apakah wisatawan siap untuk melakukan kegiatan wisata paralayang.

b. Memberi arahan untuk menggunakan peralatan keselamatan diri selama aktivitas wisata paralayang dilakukan.

c. Memberikan arahan pada saat akan terbang, saat terbang, dan saat landing atau mendarat. d. Memberi arahan dan menginstruksikan kepada wisatawan saat ingin melakukan take off.

e. Pada saat melakukan aktivitas wisata paralayang terutama saat sedang terbang, wisatawan harus tetap tenang dan tidak panik.

f. Memberi arahan pada saat akan melakukan pendaratan atau landing.

\subsubsection{Faktor-faktor Yang Mempengaruhi Terjadinya Kecelakaan}

1. Faktor Internal

a. Faktor Usia: Usia yang sudah lewat dari usia produktif dapat mengakibatkan seoserang tidak dapat beraktivitas seperti biasanya. Hal ini biasanya berkaitan dengan stamina atau kondisi fisik seseorang dan lamanya waktu dalam bekerja ataupun beraktivitas sehingga mudah lelah dan hilang fokus. Pemandu atau instruktur yang sedang lelah atau tidak dalam kondisi yang fit tidak diperbolehkan untuk mengantar atau menemani wisatawan untuk terbang karena besar resiko yang akan terjadi jika tidak sesuai prosedur.

b. Faktor Penyakit: Wisata paralayang melarang siapapun yang sedang sakit untuk menikmati atau memandu atraksi wisata paralayang, karena dapat menimbulkan resiko jika kondisi fisik tidak sehat.

c. Tidak memeriksa terlebih dahulu perlengkapan dan peralatan utama untuk terbang seperti parasut utama, harness, parasut cadangan, radio/ht, helmet, peta lokasi terbang, windmeter, variometer.

d. Tidak menggunakan peralatan safety yang wajib digunakan selama kegiatan wisata paralayang berlangsung seperti helm dan sepatu.

e. Tidak mendengarkan arahan atau instruksi yang telah diberikan dengan benar pada saat berwisata atau melakukan sesuatu yang dilarang atau diluar arahan yang diberikan oleh pemandu wisata atau instruktur.

2. Faktor Eksternal

a. Kondisi alam sangat penting untuk diperhatikan dalam aktivitas wisata 
paralayang. Karena wisata ini menggunakan sumber daya alam sebagai sumber daya utama yaitu angin, ketika angin sedang tidak bersahabat atau lebih kencang dari biasanya, maka aktivitas terbang dengan parasut ini tidak diperbolehkan, selain angin faktor cuaca lainnya seperti hujan dan waktu malam hari juga tidak disarankan untuk aktivitas wisata ini karena selain berbahaya, parasut atau instrument utama dari paralayang tidak dapat digunakan.

\subsubsection{Pencengahan Dan Penanggulangan Pada Kecelakaan}

Melakukan aktivitas wisata atau olahraga yang ekstrim besar kemungkinan menghasilkan dampak yang merugikan berbagai pihak. Dengan berbagai resiko dan dampak yang dapat ditimbulkan maka diperlukan adanya pencegahan dan penanggulangan atas resiko kecelakaan yang dapat terjadi seperti berikut:

\section{A. Pencegahan}

Agar wisatawan merasa aman saat melakukan aktivitas wisata paralayang dan menjadi suatu kepercayaan bagi wisatawan tentunya pihak pengelola usaha tandem wisata paralayang harus memperhatikan hal-hal mulai dari yang paling dasar hingga hal-hal utama untuk ditangani agar dapat mencegah terjadinya resiko kecelakaan yang dapat ditimbulkan. Resiko-resiko terjadinya kecelakaan pada wisatawan saat melakukan aktivitas wisata paralayang dapat dicegah dengan melakukan tahapantahapan sebagai berikut:

1. Mempelajari lingkungan sekitar ataupun lokasi tempat aktivitas wisata paralayang dilakukan.

2. Setiap instruktur atau pemandu wisata pada aktivitas wisata paralayang harus memiliki lisensi yang dikeluarkan oleh FASI (Federasi Aero Sport Indonesia).

3. Instruktur atau pemandu wisata pada aktivitas wisata paralayang harus memberikan instruksi yang benar kepada wisatawan sehingga aktivitas wisata yang dilakukan tidak menimbulkan resiko kecelakaan.

4. Wisatawan yang melakukan aktivitas wisata paralayang tidak boleh melakukan hal-hal diluar daripada instruksi pemandu wisata atau instruktur.

5. Meminimalisir resiko kecelakaan dengan selalu berhati-hati pada saat melakukan aktivitas wisata paralayang.

6. Wisatawan yang sedang tidak dalam kondisi tubuh yang sehat atau sakit sebaiknya tidak melakukan aktivitas wisata paralayang, karena besar kemungkinan terjadinya resiko kecelakaan.

\section{B. Penanggulangan}

Dalam mengatasi berbagai dampak atau resiko yang ditimbulkan oleh pihak Wisata Paralayang Gunung Banyak, pihak pengelola telah mengantisipasinya dengan berbagai cara sesuai dengan aturan yang telah ditetapkan dan diterapkan ditempat tersebut. Pihak pengelola wisata paralayang sendiri telah memasukan jaminan asuransi dalam setiap aktivitas wisata paralayang baik itu untuk wisatawan maupun instruktur yang sedang bekerja.

Selain asuransi, pihak pengelola wisata paralayang juga menyediakan kotak kesehatan atau P3K. dimana kotak P3K ini sangat penting keberadaannya dan diperlukan sewaktu-waktu terjadinya kecelakaan pada korban dan sebagai alat pertolongan pertama. Peralatan P3K yang disediakan oleh pihak pengelola masih bersifat umum seperti yang biasa digunakan kebanyakan orang diantaranya adalah Betadine, kapas, kasa atau perban, minyak kayu putih, pingset, perekat dan alkohol. Tujuannya adalah untuk menutupi luka sementara dan pertolongan awal sebelum korban dibawa ke rumah sakit terdekat.

Transportasi juga penting sebagai sarana pendukung utama dalam menangani korban kecelakaan yang ditimbulkan oleh aktivitas wisata paralayang. Transportasi digunakan setelah dilakukan pertolongan pertama oleh pihak pengelola dan segera diantar ke rumah sakit terdekat agar mendapatkan pertolongan dan perawatan lebih lanjut. Pihak pengelola akan melakukan pemberhentian sementara pada aktivitas 
wisata paralayang jika terjadi kecelakaan dan terdapat korban yang harus segera diberikan tindakan lebih lanjut.

\section{PENUTUP}

\subsection{Simpulan}

Aktivitas Wisata Paralayang di Gunung Banyak adalah jenis wisata ekstrim yang cukup aman dilakukan. Hal ini dapat dilihat dari berbagai aspek diantaranya:

Wisata paralayang aman dilakukan karena akan didampingi oleh instruktur atau pemandu wisata paralayang yang sudah memiliki lisensi yang dikeluarkan langsung oleh Federasi Aero Sport Indonesia (FASI) selain itu penerapan standar yang dilakukan pengelola wisata paralayang sudah sangat baik dan sesuai dengan ketentuan olahraga paralayang itu sendiri serta memberikan beberapa syarat dan memberikan petunjuk bagi wisatawan dan instruktur atau pemandu wisata yang akan melakukan aktivitas wisata agar mencegah resiko terjadinya kecelakaan. Persyaratan dan petunjuk yang diinstruksikan adalah tentang kesehatan dan fisik dari wisatawan itu sendiri serta mengikuti arahan dari instruktur guna menghindari resiko terjadinya kecelakaan. Pihak pengelola juga memberikan jaminan asuransi kepada wisatawan dan juga instruktur atau pemandu wisata saat melakukan Aktivitas Wisata Paralayang dan menyediakan beberapa obat-obatan dan keperluan lainnya saat terjadi kecelakaan.

\subsection{Saran}

Saran untuk penelitian ini adalah:

1. Untuk pengelola perlu menyediakan beberapa orang tim medis yang ahli untuk menolong dan memberikan penanganan awal terhadap korban pada saat terjadi kecelakaan. Harus membuat Prosedur kesehatan dan keselamatan kerja tertulis yang disediakan bagi wisatawan dari pihak pengelola aktivitas wisata paralayang agar wisatawan dapat lebih memahami pentingnya keselamatan dan kesehatan kerja bagi diri masing-masing. Pihak pengelola aktivitas wisata paralayang harus selalu memperhatikan dan merawat peralatan utama yang mereka miliki agar kegiatan aktivitas wisata paralayang selalu aman dan keselamatan wisatawan serta instruktur atau pemandu wisata selalu terjamin. Penerapan K3 pada wisatawan harus selalu diperhatikan dan dilakukan dengan sesuai Standar Operasional Prosedur K3 yang benar.

2. Untuk wisatawan diharapkan agar selalu mengikuti dengan baik arahan yang diberikan oleh instruktur atau pemandu wisata serta mentaati peraturan-peraturan yang telah dibuat oleh pihak pengelola wisata paralayang.

3. Diharapkan penelitian ini dapat menjadi acuan untuk prosedur penerapan K3 pada Aktivitas Wisata Paralayang di Gunung Banyak, Kota Batu, Provinsi Jawa Timur agar di penelitian selanjutnya dapat memberikan hasil yang lebih lengkap terhadap prosedur penerapan K3 pada aktivitas wisata khususnya Aktivitas Wisata Paralayang.

\section{DAFTAR PUSTAKA}

A.A. Anwar Prabu Mangkunegara. 2008. Manajemen Sumber Daya Manusia Perusahaan. Bandung: PT. Remaja Rosdakarya.

Bennet, Silalahi. 1995. Manajemen Keselamatan dan Kesehatan Kerja. Jakarta: PT. Pustaka Binaman Pressindo.

Koentjaraningrat. 1991. Metode Penelitian Masyarakat. Jakarta: Universitas Indonesia (UI-Press).

Moleong, Lexi. 2012. Metodologi Penelitian Kualitatif. Bandung: PT. Renaja Rosdakarya.

Oka A. Yoeti. 2002. Perencanaan \& Pengembangan Pariwisata. Jakarta: PT. Pradaya Paramita.

Simon, Julius. 2016. Penerapan Keselamatan dan Kesehatan Kerja Pada Aktivitas Wisata Berenang Bersama Ikan Hiu (Swim With Shark) di Pulau Serangan, Denpasar Selatan. Bali: Universitas Udayana. (Skripsi)

Suharsimi, Arikunto. 2010. Prosedur Penelitian Suatu Pendekatan Praktik. Jakarta: Rineka Cipta.

Wardani, Nila Restu. 2011. Pengembangan Objek Wisata Paralayang Berdasarkan Kajian Geografis di Kota Batu. Malang: Skripsi, Jurusan Geografi, FIS, Universitas Negeri Malang. (Skirpsi) 